\title{
Automating data extraction in systematic reviews: a systematic review
}

\author{
Siddhartha R. Jonnalagadda ${ }^{1 *}$, Pawan Goyal ${ }^{2}$ and Mark D. Huffman ${ }^{3}$
}

\begin{abstract}
Background: Automation of the parts of systematic review process, specifically the data extraction step, may be an important strategy to reduce the time necessary to complete a systematic review. However, the state of the science of automatically extracting data elements from full texts has not been well described. This paper performs a systematic review of published and unpublished methods to automate data extraction for systematic reviews.

Methods: We systematically searched PubMed, IEEEXplore, and ACM Digital Library to identify potentially relevant articles. We included reports that met the following criteria: 1) methods or results section described what entities were or need to be extracted, and 2) at least one entity was automatically extracted with evaluation results that were presented for that entity. We also reviewed the citations from included reports.

Results: Out of a total of 1190 unique citations that met our search criteria, we found 26 published reports describing automatic extraction of at least one of more than 52 potential data elements used in systematic reviews. For 25 (48 \%) of the data elements used in systematic reviews, there were attempts from various researchers to extract information automatically from the publication text. Out of these, 14 (27\%) data elements were completely extracted, but the highest number of data elements extracted automatically by a single study was 7. Most of the data elements were extracted with F-scores (a mean of sensitivity and positive predictive value) of over $70 \%$.

Conclusions: We found no unified information extraction framework tailored to the systematic review process, and published reports focused on a limited (1-7) number of data elements. Biomedical natural language processing techniques have not been fully utilized to fully or even partially automate the data extraction step of systematic reviews.
\end{abstract}

\section{Background}

Systematic reviews identify, assess, synthesize, and interpret published and unpublished evidence, which improves decision-making for clinicians, patients, policymakers, and other stakeholders [1]. Systematic reviews also identify research gaps to develop new research ideas. The steps to conduct a systematic review [1-3] are:

1. Define the review question and develop criteria for including studies

2. Search for studies addressing the review question

3. Select studies that meet criteria for inclusion in the review

4. Extract data from included studies

\footnotetext{
* Correspondence: sid@northwestern.edu

'Division of Health and Biomedical Informatics, Department of Preventive Medicine, Northwestern University Feinberg School of Medicine, 750 North Lake Shore Drive, 11th Floor, Chicago, IL 60611, USA

Full list of author information is available at the end of the article
}

5. Assess the risk of bias in the included studies, by appraising them critically

6. Where appropriate, analyze the included data by undertaking meta-analyses

7. Address reporting biases

Despite their widely acknowledged usefulness [4], the process of systematic review, specifically the data extraction step (step 4), can be time-consuming. In fact, it typically takes $2.5-6.5$ years for a primary study publication to be included and published in a new systematic review [5]. Further, within 2 years of the publication of systematic reviews, $23 \%$ are out of date because they have not incorporated new evidence that might change the systematic review's primary results [6].

Natural language processing (NLP), including text mining, involves information extraction, which is the discovery by computer of new, previously unfound information by automatically extracting information from

\section{Biomed Central}


different written resources [7]. Information extraction primarily constitutes concept extraction, also known as named entity recognition, and relation extraction, also known as association extraction. NLP handles written text at level of documents, words, grammar, meaning, and context. NLP techniques have been used to automate extraction of genomic and clinical information from biomedical literature. Similarly, automation of the data extraction step of the systematic review process through NLP may be one strategy to reduce the time necessary to complete and update a systematic review. The data extraction step is one of the most time-consuming steps of a systematic review. Automating or even semiautomating this step could substantially decrease the time taken to complete systematic reviews and thus decrease the time lag for research evidence to be translated into clinical practice. Despite these potential gains from NLP, the state of the science of automating data extraction has not been well described.

To date, there is limited knowledge and methods on how to automate the data extraction phase of the systematic reviews, despite being one of the most timeconsuming steps. To address this gap in knowledge, we sought to perform a systematic review of methods to automate the data extraction component of the systematic review process.

\section{Methods}

Our methodology was based on the Standards for Systematic Reviews set by the Institute of Medicine [8]. We conducted our study procedures as detailed below with input from the Cochrane Heart Group US Satellite.

\section{Eligibility criteria}

We included a report that met the following criteria: 1) the methods or results section describes what entities were or needed to be extracted, and 2) at least one entity was automatically extracted with evaluation results that were presented for that entity.

We excluded a report that met any of the following criteria: 1) the methods were not applied to the data extraction step of a systematic review; 2) the report was an editorial, commentary, or other non-original research report; or 3) there was no evaluation component.

\section{Information sources and searches}

For collecting the initial set of articles for our review, we developed search strategies with the help of the Cochrane Heart Group US Satellite, which includes systematic reviewers and a medical librarian. We refined these strategies using relevant citations from related papers. We searched three datasets: PubMed, IEEExplore, and ACM digital library, and our searches were limited between January 1, 2000 and January 6, 2015 (see Appendix 1). We restricted our search to these dates because biomedical information extraction algorithms prior to 2000 are unlikely to be accurate enough to be used for systematic reviews.

We retrieved articles that dealt with the extraction of various data elements, defined as categories of data that pertained to any information about or deriving from a study, including details of methods, participants, setting, context, interventions, outcomes, results, publications, and investigators [1] from included study reports. After we retrieved the initial set of reports from the search results, we then evaluated reports included in the references of these reports. We also sought expert opinion for additional relevant citations.

\section{Study selection}

We first de-duplicated the retrieve citations. For calibration and refinement of the inclusion and exclusion criteria, 100 citations were randomly selected and independently reviewed by a two authors (SRJ and PG). Disagreements were resolved by consensus with a third author $(\mathrm{MH})$. In a second round, another set of 100 randomly selected abstracts was independently reviewed by two study authors (SRJ and PG), whereby we achieved a strong level of agreement $(\mathrm{kappa}=0.97)$. Given the high level of agreement, the remaining studies were reviewed only by one author (PG). In this phase, we identified reports as "not relevant" or "potentially relevant".

Two authors (PG and SRJ) independently reviewed the full text of all citations $(N=74)$ that were identified as "potentially relevant". We classified included reports into various categories based on the particular data element that they attempted to extract from the original, scientific articles. Example of these data elements might be overall evidence, specific interventions, among others (Table 1). We resolved disagreements between the two reviewers through consensus with a third author (MDH).

\section{Data collection process}

Two authors (PG and SRJ) independently reviewed the included articles to extract data, such as the particular entity automatically extracted by the study, algorithm or technique used, and evaluation results into a data abstraction spreadsheet. We resolved disagreements through consensus with a third author (MDH).

\section{Data items}

We reviewed the Cochrane Handbook for Systematic Reviews [1], the CONsolidated Standards Of Reporting Trials (CONSORT) [9] statement, the Standards for Reporting of Diagnostic Accuracy (STARD) initiative [10], and PICO [11], PECODR [12], and PIBOSO [13] frameworks to obtain the data elements to be considered. PICO stands for Population, Intervention, Comparison, Outcomes; PECODR stands for Patient-Population-Problem, 
Table 1 Data elements, category, sources and existing automation work

\begin{tabular}{|c|c|c|c|}
\hline Data element & Category & Included in standards & Published method to extract? \\
\hline Total number of participants & Participants & Cochrane, PICO, PECODR, PIBOSO, STARD & Yes $[12,13,16-20,23,24,28-30,32,39]$ \\
\hline Settings & Participants & Cochrane, CONSORT, STARD & No \\
\hline Diagnostic criteria & Participants & Cochrane, STARD & No \\
\hline Age & Participants & Cochrane, STARD & Yes $[24,29,39,41]$ \\
\hline Sex & Participants & Cochrane, STARD & Yes $[24,29,41]$ \\
\hline Country & Participants & Cochrane & Yes $[24,39]$ \\
\hline Co-morbidity & Participants & Cochrane, STARD & Yes [21] \\
\hline Socio-demographics & Participants & Cochrane, STARD & No \\
\hline $\begin{array}{l}\text { Spectrum of presenting symptoms, } \\
\text { current treatments, recruitment centers }\end{array}$ & Participants & STARD & Yes $[21,24,28,29,32,41]$ \\
\hline Ethnicity & Participants & Cochrane & Yes [41] \\
\hline Date of study & Participants & Cochrane & Yes [39] \\
\hline Date of recruitment and follow-up & Participants & CONSORT, STARD & No \\
\hline Participant sampling & Participants & STARD & No \\
\hline Total number of intervention groups & Intervention & Cochrane & Yes $[34,35]$ \\
\hline Specific intervention & Intervention & Cochrane, PICO, PIBOSO, PECODR & Yes $[12,13,16-20,22,24,28,34,39,40]$ \\
\hline $\begin{array}{l}\text { Intervention details (sufficient for replication, } \\
\text { if feasible) }\end{array}$ & Intervention & Cochrane, CONSORT & Yes [36] \\
\hline Integrity of intervention & Intervention & Cochrane & No \\
\hline $\begin{array}{l}\text { Outcomes and time points (i) collected; } \\
\text { (ii) reported }\end{array}$ & Outcomes & $\begin{array}{l}\text { Cochrane, CONSORT, PICO, PECODR, } \\
\text { PIBOSO }\end{array}$ & Yes $[12,13,16-20,24,25,28,34-36,40]$ \\
\hline $\begin{array}{l}\text { Outcome definition (with diagnostic criteria } \\
\text { if relevant) }\end{array}$ & Outcomes & Cochrane & No \\
\hline Unit of measurement (if relevant) & Outcomes & Cochrane & No \\
\hline $\begin{array}{l}\text { For scales: upper and lower limits, and } \\
\text { whether high or low score is good }\end{array}$ & Outcomes & Cochrane & No \\
\hline Comparison & Comparisons & PICO, PECODR & Yes $[12,16,22,23]$ \\
\hline Sample size & Results & Cochrane, CONSORT & Yes $[36,40]$ \\
\hline Missing participants & Results & Cochrane & No \\
\hline $\begin{array}{l}\text { Summary data for each intervention group } \\
\text { (e.g. } 2 \times 2 \text { table for dichotomous data; means } \\
\text { and SDs for continuous data) }\end{array}$ & Results & Cochrane, PECODR, STARD & No \\
\hline $\begin{array}{l}\text { Estimate of effect with confidence interval; } \\
P \text { value }\end{array}$ & Results & Cochrane & No \\
\hline Subgroup analyses & Results & Cochrane & No \\
\hline $\begin{array}{l}\text { Adverse events and side effects for each } \\
\text { study group }\end{array}$ & Results & CONSORT, STARD & No \\
\hline Overall evidence & Interpretation & CONSORT & Yes $[26,42]$ \\
\hline $\begin{array}{l}\text { Generalizability: external validity of trial } \\
\text { findings }\end{array}$ & Interpretation & CONSORT & Yes [25] \\
\hline Research questions and hypotheses & Objectives & CONSORT, PECODR, PIBOSO, STARD & Yes $[24,25]$ \\
\hline Reference standard and its rationale & Method & STARD & No \\
\hline $\begin{array}{l}\text { Technical specifications of material and } \\
\text { methods involved including how and } \\
\text { when measurements were taken, } \\
\text { and/or cite references for index tests } \\
\text { and reference standard }\end{array}$ & Method & STARD & No \\
\hline Study design & Method & Cochrane, PIBOSO & Yes $[13,18,20,24]$ \\
\hline Total study duration & Method & Cochrane, PECODR & Yes $[12,29,40]$ \\
\hline
\end{tabular}


Table 1 Data elements, category, sources and existing automation work (Continued)

\begin{tabular}{|c|c|c|c|}
\hline Sequence generation & Method & Cochrane & Yes [27] \\
\hline Allocation sequence concealment & Method & Cochrane & Yes [27] \\
\hline Blinding & Method & Cochrane, CONSORT, STARD & Yes [27] \\
\hline $\begin{array}{l}\text { Methods used to generate random } \\
\text { allocation sequence, implementation }\end{array}$ & Method & CONSORT, STARD & Yes [25] \\
\hline Other concerns about bias & Method & Cochrane & No \\
\hline $\begin{array}{l}\text { Methods used to compare groups for primary } \\
\text { outcomes and for additional analyses }\end{array}$ & Method & CONSORT, STARD & No \\
\hline Methods for calculating test reproducibility & Method & STARD & No \\
\hline $\begin{array}{l}\text { Definition and rationale for the units, cutoffs } \\
\text { and/or categories of the results of the index } \\
\text { tests and reference standard }\end{array}$ & Method & STARD & No \\
\hline $\begin{array}{l}\text { Number, training, and expertise of the persons } \\
\text { executing and reading the index tests and } \\
\text { the reference standard }\end{array}$ & Method & STARD & No \\
\hline $\begin{array}{l}\text { Participant flow: flow of participants through } \\
\text { each stage: randomly assigned, received } \\
\text { intended treatment, completed study, } \\
\text { analyzed for primary outcome, inclusion } \\
\text { and exclusion criteria }\end{array}$ & Method & CONSORT & Yes $[36,37,40]$ \\
\hline Funding source & Miscellaneous & Cochrane & No \\
\hline Key conclusions of the study authors & Miscellaneous & Cochrane & Yes [26] \\
\hline Clinical applicability of the study findings & Miscellaneous & STARD & No \\
\hline $\begin{array}{l}\text { Miscellaneous comments from the } \\
\text { study authors }\end{array}$ & Miscellaneous & Cochrane & No \\
\hline References to other relevant studies & Miscellaneous & Cochrane & No \\
\hline Correspondence required & Miscellaneous & Cochrane & No \\
\hline Miscellaneous comments by the review & Miscellaneous & Cochrane & No \\
\hline
\end{tabular}

Exposure-Intervention, Comparison, Outcome, Duration and Results; and PIBOSO stands for Population, Intervention, Background, Outcome, Study Design, Other.

\section{Data synthesis and analysis}

Because of the large variation in study methods and measurements, a meta-analysis of methodological features and contextual factors associated with the frequency of data extraction methods was not possible. We therefore present a narrative synthesis of our findings. We did not thoroughly assess risk of bias, including reporting bias, for these reports because the study designs did not match domains evaluated in commonly used instruments such as the Cochrane Risk of Bias tool [1] or QUADAS-2 instrument used for systematic reviews of randomized trials and diagnostic test accuracy studies, respectively [14].

\section{Results}

\section{Study selection}

Of 1190 unique citations retrieved, we selected 75 reports for full-text screening, and we included 26 articles that met our inclusion criteria (Fig. 1). Agreement on abstract and full-text screening was 0.97 and 1.00.

\section{Study characteristics}

Table 1 provides a list of items to be considered in the data extraction process based on the Cochrane Handbook (Appendix 2) [1], CONSORT statement [9], STARD initiative [10], and PICO [11], PECODR [12], and PIBOSO [13] frameworks. We provide the major group for each field and report which standard focused on that field. Finally, we report whether there was a published method to extract that field. Table 1 also identifies the data elements relevant to systematic review process categorized by their domain and the standard from which the element was adopted and was associated with existing automation methods, where present.

\section{Results of individual studies}

Table 2 summarizes the existing information extraction studies. For each study, the table provides the citation to the study (study: column 1), data elements that the study focused on (extracted elements: column 2), dataset used by the study (dataset: column 3), algorithm and methods used for extraction (method: column 4), whether the study extracted only the sentence containing the data elements, full concept or neither of these (sentence/ 


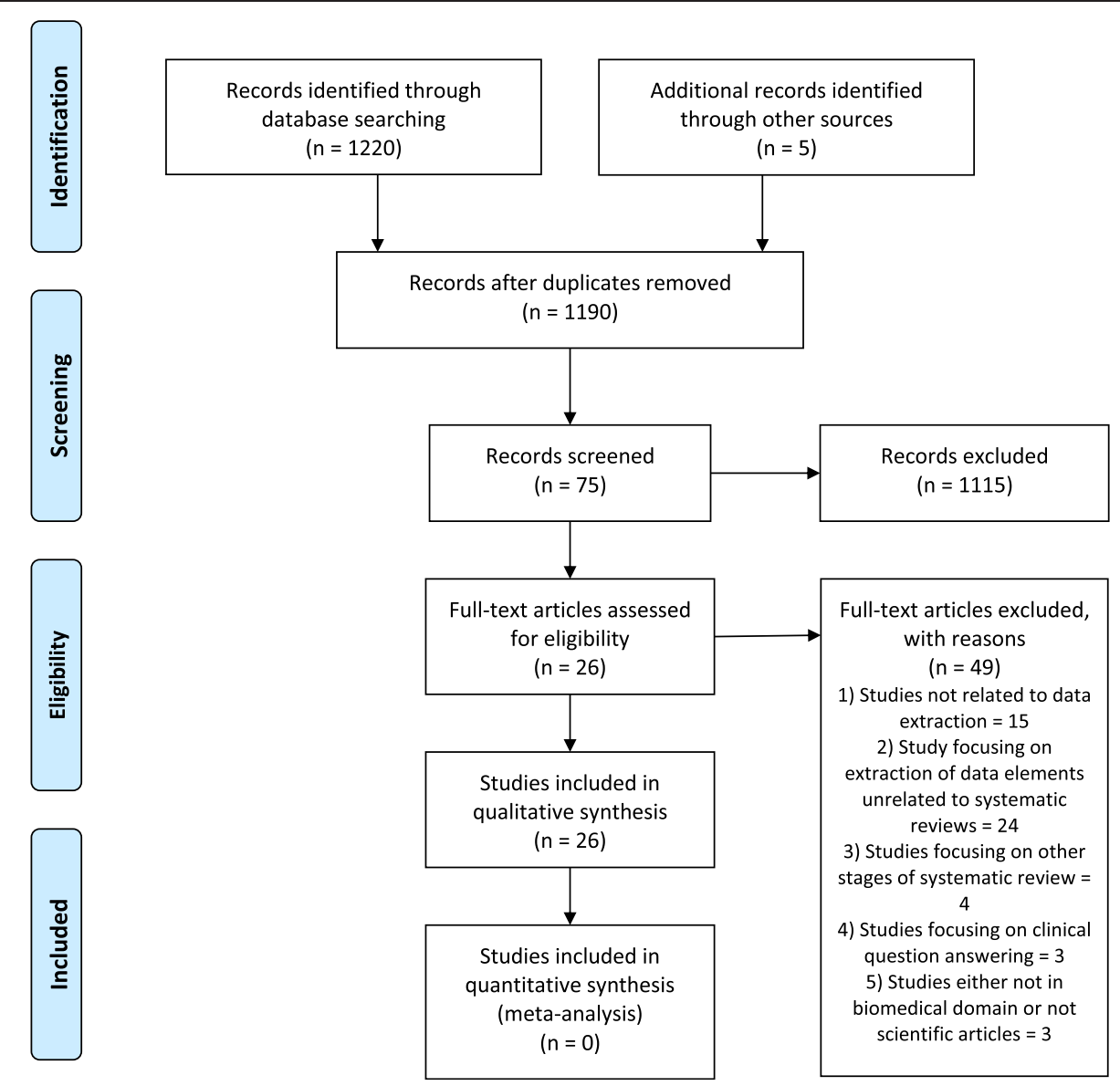

Fig. 1 Process of screening the articles to be included for this systematic review

concept/neither: column 5), whether the extraction was done from full-text or abstracts (full text/abstract: column 6) and the main accuracy results reported by the system (results: column 7). The studies are arranged by increasing complexity by ordering studies that classified sentences before those that extracted the concepts and ordering studies that extracted data from abstracts before those that extracted data from full-text reports.

The accuracy of most $(N=18,69 \%)$ studies was measured using a standard text mining metric known as F-score, which is the harmonic mean of precision (positive predictive value) and recall (sensitivity). Some studies $(N=5,19 \%)$ reported only the precision of their method, while some reported the accuracy values $(N=2$, $8 \%$ ). One study (4\%) reported P5 precision, which indicates the fraction of positive predictions among the top 5 results returned by the system.

\section{Studies that did not implement a data extraction system} Dawes et al. [12] identified 20 evidence-based medicine journal synopses with 759 extracts in the corresponding PubMed abstracts. Annotators agreed with the identification of an element 85 and $87 \%$ for the evidence-based medicine synopses and PubMed abstracts, respectively. After consensus among the annotators, agreement rose to 97 and $98 \%$, respectively. The authors proposed various lexical patterns and developed rules to discover each PECODR element from the PubMed abstracts and the corresponding evidence-based medicine journal synopses that might make it possible to partially or fully automate the data extraction process.

\section{Studies that identified sentences but did not extract data elements from abstracts only}

Kim et al. [13] used conditional random fields (CRF) [15] for the task of classifying sentences in one of the PICO categories. The features were based on lexical, syntactic, structural, and sequential information in the data. The authors found that unigrams, section headings, and sequential information from preceding sentences were useful features for the classification task. They used 1000 medical abstracts from PIBOSO corpus and achieved micro-averaged F-scores of 91 and $67 \%$ over datasets of structured and unstructured abstracts, respectively. 
Table 2 A summary of included extraction methods and their evaluation

\begin{tabular}{|c|c|c|c|c|c|c|}
\hline Study & Extracted elements & Dataset & Method & Sentence/Concept/Neither & Full text (F)/Abstract (A) & Results \\
\hline $\begin{array}{l}\text { Dawes et al. } \\
\text { (2007) [12] }\end{array}$ & PECODR & $\begin{array}{l}20 \text { evidence-based } \\
\text { medicine journal } \\
\text { synopses ( } 759 \\
\text { extracts from the } \\
\text { corresponding } \\
\text { PubMed abstracts) }\end{array}$ & $\begin{array}{l}\text { Proposed potential lexical } \\
\text { patterns and assessed } \\
\text { using NVlvo software }\end{array}$ & Neither & Abstract & $\begin{array}{l}\text { Agreement among the annotators was } \\
86.6 \text { and } 85 \% \text {, which rose up to } 98.4 \\
\text { and } 96.9 \% \text { after consensus. No } \\
\text { automated system. }\end{array}$ \\
\hline $\begin{array}{l}\text { Kim et al. } \\
\text { (2011) [13] }\end{array}$ & PIBOSO & $\begin{array}{l}1000 \text { medical abstracts } \\
\text { (PIBOSO corpus) }\end{array}$ & $\begin{array}{l}\text { Conditional random fields } \\
\text { with various features } \\
\text { based on lexical, } \\
\text { semantic, structural and } \\
\text { sequential information }\end{array}$ & Sentence & Abstract & $\begin{array}{l}\text { Micro-averaged F-scores on structured } \\
\text { and unstructured: } 80.9 \text { and } 66.9 \% \text {, } \\
63.1 \% \text { on an external dataset }\end{array}$ \\
\hline $\begin{array}{l}\text { Boudin et al. } \\
\text { (2010) [16] }\end{array}$ & $\begin{array}{l}\mathrm{PICO} \text { (I and C were } \\
\text { combined together) }\end{array}$ & $\begin{array}{l}26,000 \text { abstracts from PubMed, } \\
\text { first sentences from the } \\
\text { structured abstract }\end{array}$ & $\begin{array}{l}\text { Combination of multiple } \\
\text { supervised classification } \\
\text { algorithms: random } \\
\text { forests (RF), naive Bayes } \\
\text { (NB), support vector } \\
\text { machines (SVM), and } \\
\text { multi-layer perceptron } \\
\text { (MLP) }\end{array}$ & Sentence & Abstract & $\begin{array}{l}\text { F-score of } 86.3 \% \text { for } P, 67 \% \text { for I } \\
\text { (and C), and } 56.3 \% \text { for O }\end{array}$ \\
\hline $\begin{array}{l}\text { Huang et al. } \\
\text { (2011) [17] }\end{array}$ & PICO (except C) & $\begin{array}{l}23,472 \text { sentences from the } \\
\text { structured abstracts }\end{array}$ & naïve Bayes & Sentence & Abstract & $\begin{array}{l}\text { F-measure of } 0.91 \text { for patient/problem, } \\
0.75 \text { for intervention, and } 0.88 \text { for } \\
\text { outcome }\end{array}$ \\
\hline $\begin{array}{l}\text { Verbeke et al. } \\
\text { (2012) [18] }\end{array}$ & PIBOSO & PIBOSO corpus & $\begin{array}{l}\text { Statistical relational } \\
\text { learning with kernels, } \\
\text { kLog }\end{array}$ & Sentence & Abstract & $\begin{array}{l}\text { Micro-averaged F of } 84.29 \% \text { on } \\
\text { structured abstracts and } 67.14 \% \text { on } \\
\text { unstructured abstracts }\end{array}$ \\
\hline \multirow[t]{2}{*}{$\begin{array}{l}\text { Huang et al. } \\
\text { (2013) [19] }\end{array}$} & \multirow[t]{2}{*}{ PICO (except C) } & \multirow[t]{2}{*}{$\begin{array}{l}19,854 \text { structured abstracts of } \\
\text { randomized controlled trials }\end{array}$} & \multirow{2}{*}{$\begin{array}{l}\text { First sentence of the } \\
\text { section or all sentences in } \\
\text { the section, NB classifier }\end{array}$} & \multirow[t]{2}{*}{ Sentence } & \multirow[t]{2}{*}{ Abstract } & $\begin{array}{l}\text { First sentence of the section: F-scores } \\
\text { for P: } 0.74,1: 0.66 \text {, and } O: 0.73\end{array}$ \\
\hline & & & & & & $\begin{array}{l}\text { All sentences in the section: F-scores } \\
\text { for P: } 0.73,1: 0.73 \text {, and } 0: 0.74\end{array}$ \\
\hline $\begin{array}{l}\text { Hassanzadeh } \\
\text { et al. (2014) } \\
\text { [20] }\end{array}$ & $\begin{array}{l}\text { PIBOSO (Population- } \\
\text { Intervention-Background- } \\
\text { Outcome-Study } \\
\text { Design-Other) }\end{array}$ & $\begin{array}{l}\text { PIBOSO corpus, } 1000 \\
\text { structured and unstructured } \\
\text { abstracts }\end{array}$ & $\begin{array}{l}\text { CRF with discriminate set } \\
\text { of features }\end{array}$ & Sentence & Abstract & Micro-averaged F-score: 91 \\
\hline $\begin{array}{l}\text { Robinson } \\
\text { (2012) [21] }\end{array}$ & $\begin{array}{l}\text { Patient-oriented evidence: } \\
\text { morbidity, morality, } \\
\text { symptom severity, } \\
\text { quality of life }\end{array}$ & 1356 PubMed abstracts & $\begin{array}{l}\text { SVM, NB, multinomial NB, } \\
\text { logistic regression }\end{array}$ & Sentence & Abstract & $\begin{array}{l}\text { Best results achieved via SVM: } \\
\text { F-measure of } 0.86\end{array}$ \\
\hline $\begin{array}{l}\text { Chung (2009) } \\
\text { [22] }\end{array}$ & Intervention, comparisons & $\begin{array}{l}203 \mathrm{RCT} \text { abstracts for training } \\
\text { and } 124 \text { for testing }\end{array}$ & $\begin{array}{l}\text { Coordinating constructs } \\
\text { are identified using a full } \\
\text { parser, which are further } \\
\text { classified as positive or } \\
\text { not using CRF }\end{array}$ & Sentence & Abstract & F-score: 0.76 \\
\hline $\begin{array}{l}\text { Hara and } \\
\text { Matsumoto } \\
\text { (2007) [23] }\end{array}$ & $\begin{array}{l}\text { Patient population, } \\
\text { comparison }\end{array}$ & $\begin{array}{l}200 \text { abstracts labeled as } \\
\text { 'Neoplasms' and 'Clinical Trial, } \\
\text { Phase III' }\end{array}$ & $\begin{array}{l}\text { Categorizing noun } \\
\text { phrases (NPs) into classes } \\
\text { such as 'Disease', }\end{array}$ & Sentence & Abstract & $\begin{array}{l}\text { F-measure of } 0.91 \text { for the task of noun } \\
\text { phrase classification. Results of sentence } \\
\text { classification: F-,measure of } 0.8 \text { for }\end{array}$ \\
\hline
\end{tabular}


Table 2 A summary of included extraction methods and their evaluation (Continued)

\begin{tabular}{|c|c|c|c|c|c|}
\hline & & & $\begin{array}{l}\text { 'Treatment' etc. using CRF } \\
\text { and use regular } \\
\text { expressions on the } \\
\text { sentence with classified } \\
\text { Noun Phrases }\end{array}$ & & \\
\hline $\begin{array}{l}\text { Davis- } \\
\text { Desmond and } \\
\text { Molla (2012) } \\
\text { [42] }\end{array}$ & $\begin{array}{l}\text { Detecting statistical } \\
\text { evidence }\end{array}$ & $\begin{array}{l}194 \text { randomized controlled trial } \\
\text { abstracts from PubMed }\end{array}$ & $\begin{array}{l}\text { Rule-based classifier using } \\
\text { negation expressions }\end{array}$ & Sentence & Abstract \\
\hline $\begin{array}{l}\text { Zhao et al. } \\
\text { (2012) [24] }\end{array}$ & $\begin{array}{l}\text { Patient, result, } \\
\text { Intervention, Study } \\
\text { Design, Research Goal }\end{array}$ & $\begin{array}{l}19,893 \text { medical abstracts and } \\
\text { full text articles from } 17 \text { journal } \\
\text { websites }\end{array}$ & Conditional random fields & Sentence & Full text \\
\hline $\begin{array}{l}\text { Hsu et al. } \\
\text { (2012) [25] }\end{array}$ & $\begin{array}{l}\text { Hypothesis, statistical } \\
\text { method, outcomes and } \\
\text { generalizability }\end{array}$ & 42 full-text papers & Regular expressions & Sentence & Full text \\
\hline $\begin{array}{l}\text { Song et al. } \\
\text { (2013) [26] }\end{array}$ & $\begin{array}{l}\text { Analysis (statistical facts), } \\
\text { general (generally } \\
\text { accepted facts), } \\
\text { recommend } \\
\text { (recommendations about } \\
\text { interventions), rule } \\
\text { (guidelines) }\end{array}$ & $\begin{array}{l}346 \text { sentences from three } \\
\text { clinical guideline document }\end{array}$ & $\begin{array}{l}\text { Maximum entropy } \\
\text { (MaxEnt), SVM, MLP, radial } \\
\text { basis function network } \\
\text { (RBFN), NB as classifiers } \\
\text { and information gain (IG), } \\
\text { genetic algorithm (GA) for } \\
\text { feature selection }\end{array}$ & Sentence & Full text \\
\hline $\begin{array}{l}\text { Demner- } \\
\text { Fushman and } \\
\text { Lin (2007) [28] }\end{array}$ & $\begin{array}{l}\text { PICO }(I \text { and } C \text { were } \\
\text { combined })\end{array}$ & $\begin{array}{l}275 \text { manually annotated } \\
\text { abstracts }\end{array}$ & $\begin{array}{l}\text { Rule-based approach to } \\
\text { identify sentence } \\
\text { containing PICO and } \\
\text { supervised classifier for } \\
\text { Outcomes }\end{array}$ & Concept & Abstract \\
\hline $\begin{array}{l}\text { Kelly and Yang } \\
\text { (2013) [29] }\end{array}$ & $\begin{array}{l}\text { Age of subjects, duration } \\
\text { of study, ethnicity of } \\
\text { subjects, gender of } \\
\text { subjects, health status of } \\
\text { subjects, number of } \\
\text { subjects }\end{array}$ & $\begin{array}{l}386 \text { abstracts from } \\
\text { PubMed obtained } \\
\text { with the query } \\
\text { 'soy and cancer' }\end{array}$ & $\begin{array}{l}\text { Regular expressions, } \\
\text { gazetteer }\end{array}$ & Concept & Abstract \\
\hline $\begin{array}{l}\text { Hansen et al. } \\
\text { (2008) [30] }\end{array}$ & $\begin{array}{l}\text { Number of trial } \\
\text { participants }\end{array}$ & 233 abstracts from PubMed & Support vector machines & Concept & Abstract \\
\hline $\begin{array}{l}\text { Xu et al. } \\
\text { (2007) [32] }\end{array}$ & $\begin{array}{l}\text { Subject demographics } \\
\text { such as subject } \\
\text { descriptors, number of } \\
\text { participants and diseases/ } \\
\text { symptoms and their } \\
\text { descriptors }\end{array}$ & $\begin{array}{l}250 \text { randomized controlled trial } \\
\text { abstracts }\end{array}$ & $\begin{array}{l}\text { Text classification } \\
\text { augmented with hidden } \\
\text { Markov models was used } \\
\text { to identify sentences; } \\
\text { rules over parse tree to } \\
\text { extract relevant } \\
\text { information }\end{array}$ & Sentence, concept & Abstract \\
\hline $\begin{array}{l}\text { Summerscales } \\
\text { et al. (2009) } \\
\text { [34] }\end{array}$ & $\begin{array}{l}\text { Treatments, groups and } \\
\text { outcomes }\end{array}$ & $\begin{array}{l}100 \text { abstracts } \\
\text { from } B M J\end{array}$ & Conditional random fields & Concept & Abstract \\
\hline
\end{tabular}

patient population and 0.81 for comparisons

Accuracy: between 88 and $98 \%$ at $95 \% \mathrm{Cl}$

F-scores for sentence classification: patient: 0.75 , intervention: 0.61 , result: 0.91 , study design: 0.79 , research goal 0.76

For classification task, F-score of 0.86 for hypothesis, 0.84 for statistical method, 0.9 for outcomes, and 0.59 for generalizability

F-score of 0.98 for classifying sentences

(MaxEnt), SVM, MLP, radial

basis function network

and information gain $(I G)$

Outcomes

stract

duration of study: 0.911, ethnicity of subjects: 0.949 , gender of subjects: 1.0, health status of subjects: 0.874 , number of subjects: 0.963

\section{F-measure: 0.86}

Precision for subject descriptors: $0.83 \%$ number of trial participants: 0.923 , diseases/symptoms: $51.0 \%$, descriptors of diseases/symptoms: $92.0 \%$

F-scores for treatments: 0.49 , groups: 0.82 , outcomes: 0.54 
Table 2 A summary of included extraction methods and their evaluation (Continued)

\begin{tabular}{|c|c|c|c|c|c|c|}
\hline $\begin{array}{l}\text { Summerscales } \\
\text { et al. (2011) } \\
\text { [35] }\end{array}$ & $\begin{array}{l}\text { Groups, outcomes, group } \\
\text { sizes, outcome numbers }\end{array}$ & $\begin{array}{l}263 \text { abstracts from BMJ } \\
\text { between } 2005 \text { and } 2009\end{array}$ & $\begin{array}{l}\text { CRF, MaxEnt, template } \\
\text { filling }\end{array}$ & Concept & Abstract & $\begin{array}{l}\text { F-scores for groups: } 0.76 \text {, outcomes: } \\
0.42 \text {, group sizes: } 0.80 \text {, outcome } \\
\text { numbers: } 0.71\end{array}$ \\
\hline $\begin{array}{l}\text { Kiritchenko } \\
\text { et al. (2010) } \\
\text { [36] }\end{array}$ & $\begin{array}{l}\text { Eligibility criteria, sample } \\
\text { size, drug dosage, } \\
\text { primary outcomes }\end{array}$ & $\begin{array}{l}50 \text { full-text journal } \\
\text { articles with } 1050 \\
\text { test instances }\end{array}$ & $\begin{array}{l}\text { SVM classifier to recover } \\
\text { relevant sentences, } \\
\text { extraction rules for correct } \\
\text { solutions }\end{array}$ & Concept & Full text & $\begin{array}{l}\text { P5 precision for the classifier: } 0.88, \\
\text { precision and recall of the extraction } \\
\text { rules: } 93 \text { and } 91 \% \text {, respectively }\end{array}$ \\
\hline $\begin{array}{l}\text { Lin et al. } \\
\text { (2010) [39] }\end{array}$ & $\begin{array}{l}\text { Intervention, age group } \\
\text { of the patients, } \\
\text { geographical area, } \\
\text { number of patients, time } \\
\text { duration of the study }\end{array}$ & $\begin{array}{l}93 \text { open access } \\
\text { full-text literature documenting } \\
\text { oncological and cardio-vascular } \\
\text { studies from } 2005 \\
\text { to } 2008\end{array}$ & $\begin{array}{l}\text { Linear chain, conditional } \\
\text { random fields }\end{array}$ & Concept & Full text & $\begin{array}{l}\text { Precision of } 0.4 \text { for intervention, } 0.63 \text { for } \\
\text { age group, } 0.44 \text { for geographical area, } \\
0.43 \text { for number of patients and } 0.83 \\
\text { for time period }\end{array}$ \\
\hline $\begin{array}{l}\text { Restificar et al. } \\
\text { (2012) [37] }\end{array}$ & Eligibility criteria & $\begin{array}{l}44,203 \text { full-text articles with } \\
\text { clinical trials }\end{array}$ & $\begin{array}{l}\text { Latent Dirichlet allocation } \\
\text { along with logistic } \\
\text { regression }\end{array}$ & Concept & Full text & $\begin{array}{l}75 \text { and } 70 \% \text { accuracy based on } \\
\text { similarity for inclusion and exclusion } \\
\text { criteria, respectively. }\end{array}$ \\
\hline $\begin{array}{l}\text { De Bruijn et al. } \\
\text { (2008) [40] }\end{array}$ & $\begin{array}{l}\text { Eligibility criteria, sample } \\
\text { size, treatment duration, } \\
\text { intervention, primary and } \\
\text { secondary outcomes }\end{array}$ & $\begin{array}{l}88 \text { randomized } \\
\text { controlled trials } \\
\text { full-text articles from } \\
\text { five medical journals }\end{array}$ & $\begin{array}{l}\text { SVM classifier to identify } \\
\text { the most promising } \\
\text { sentences; manually } \\
\text { crafted weak extraction } \\
\text { rules for the information } \\
\text { elements }\end{array}$ & Sentence, concept & Full text & $\begin{array}{l}\text { Precision for eligibility criteria: } 0.69, \\
\text { sample size: } 0.62 \text {, treatment duration: } \\
0.94 \text {, intervention: } 0.67 \text {, primary } \\
\text { outcome: } 1.00 \text {, secondary outcome: } \\
0.67\end{array}$ \\
\hline $\begin{array}{l}\text { Zhu et al. } \\
\text { (2012) [41] }\end{array}$ & $\begin{array}{l}\text { Subject demographics: } \\
\text { patient age, gender, } \\
\text { disease and ethnicity }\end{array}$ & $\begin{array}{l}50 \text { randomized } \\
\text { controlled trials } \\
\text { full-text articles }\end{array}$ & $\begin{array}{l}\text { Manually crafted rules for } \\
\text { extraction from the parse } \\
\text { tree }\end{array}$ & Concept & Full text & $\begin{array}{l}\text { Disease extraction: for exact matching, } \\
\text { the F-score was } 0.64 \text {. For partially } \\
\text { matched, it was } 0.85 \text {. }\end{array}$ \\
\hline $\begin{array}{l}\text { Marshall et al. } \\
\text { (2014) [27] }\end{array}$ & $\begin{array}{l}\text { Risk of bias concerning } \\
\text { sequence generation, } \\
\text { allocation concealment } \\
\text { and blinding }\end{array}$ & 2200 clinical trial reports & $\begin{array}{l}\text { Soft-margin SVM for a } \\
\text { joint model of risk of bias } \\
\text { prediction and supporting } \\
\text { sentence extraction }\end{array}$ & Sentence & Full text & $\begin{array}{l}\text { For sentence identification: F-score of } \\
0.56,0.48,0.35 \text { and } 0.38 \text { for random } \\
\text { sequence generation, allocation } \\
\text { concealment, blinding of participants } \\
\text { and personnel, and blinding of } \\
\text { outcome assessment }\end{array}$ \\
\hline
\end{tabular}


Table 3 Checklist of items to consider in data collection or data extraction from Cochrane Handbook [1]

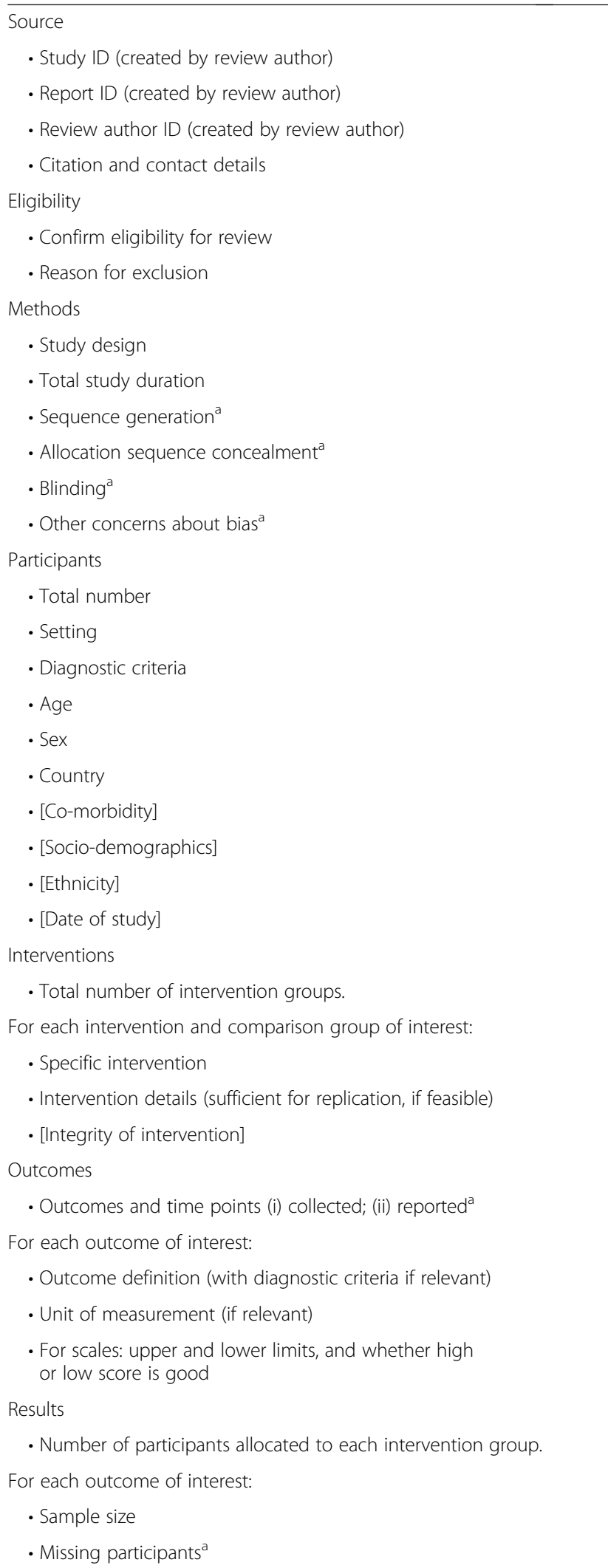

Table 3 Checklist of items to consider in data collection or data extraction from Cochrane Handbook [1] (Continued)

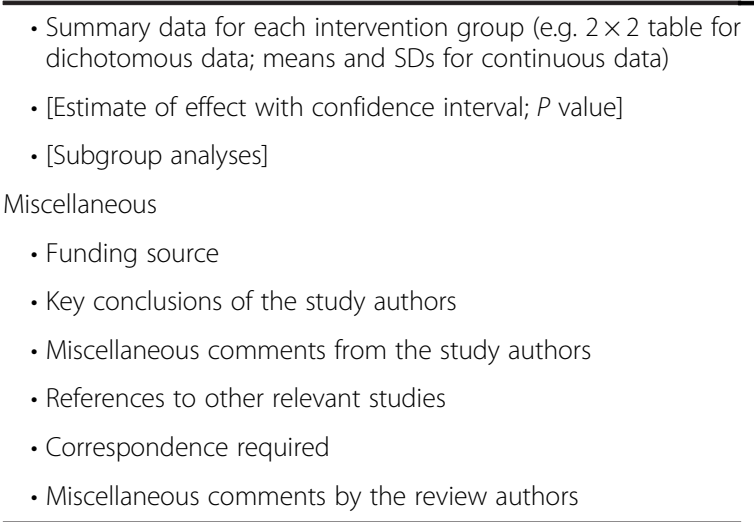

Items without parentheses should normally be collected in all reviews; items in square brackets may be relevant to some reviews and not to others

${ }^{\text {a}}$ Full description required for standard items in the 'Risk of bias' tool

Boudin et al. [16] utilized a combination of multiple supervised classification techniques for detecting PICO elements in the medical abstracts. They utilized features such as $\mathrm{MeSH}$ semantic types, word overlap with title, number of punctuation marks on random forests (RF), naive Bayes (NB), support vector machines (SVM), and multi-layer perceptron (MLP) classifiers. Using 26,000 abstracts from PubMed, the authors took the first sentence in the structured abstracts and assigned a label automatically to build a large training data. They obtained an F-score of $86 \%$ for identifying participants (P), $67 \%$ for interventions (I) and controls $(\mathrm{C})$, and $56 \%$ for outcomes $(\mathrm{O})$.

Huang et al. [17] used a naive Bayes classifier for the PICO classification task. The training data were generated automatically from the structured abstracts. For instance, all sentences in the section of the structured abstract that started with the term "PATIENT" were used to identify participants $(\mathrm{P})$. In this way, the authors could generate a dataset of 23,472 sentences. Using 23,472 sentences from the structured abstracts, they obtained an F-score of $91 \%$ for identifying participants (P), $75 \%$ for interventions (I), and $88 \%$ for outcomes $(\mathrm{O})$.

Verbeke et al. [18] used a statistical relational learningbased approach (kLog) that utilized relational features for classifying sentences. The authors also used the PIBOSO corpus for evaluation and achieved micro-averaged Fscore of $84 \%$ on structured abstracts and $67 \%$ on unstructured abstracts, which was a better performance than Kim et al. [13].

Huang et al. [19] used 19,854 structured extracts and trained two classifiers: one by taking the first sentences of each section (termed CF by the authors) and the other by taking all the sentences in each section (termed CA by the authors). The authors used the naive Bayes classifier and achieved F-scores of 74, 66, and $73 \%$ for identifying participants $(\mathrm{P})$, interventions $(\mathrm{I})$, and outcomes $(\mathrm{O})$, 
respectively, by the $\mathrm{CF}$ classifier. The $\mathrm{CA}$ classifier gave $\mathrm{F}$ scores of 73,73 , and $74 \%$ for identifying participants $(\mathrm{P})$, interventions (I), and outcomes $(\mathrm{O})$, respectively.

Hassanzadeh et al. [20] used the PIBOSO corpus for the identification of sentences with PIBOSO elements. Using conditional random fields (CRF) with discriminative set of features, they achieved micro-averaged F-score of $91 \%$.

Robinson [21] used four machine learning models, 1) support vector machines, 2) naive Bayes, 3) naive Bayes multinomial, and 4) logistic regression to identify medical abstracts that contained patient-oriented evidence or not. These data included morbidity, mortality, symptom severity, and health-related quality of life. On a dataset of 1356 PubMed abstracts, the authors achieved the highest accuracy using a support vector machines learning model and achieved an F-measure of $86 \%$.

Chung [22] utilized a full sentence parser to identify the descriptions of the assignment of treatment arms in clinical trials. The authors used predicate-argument structure along with other linguistic features with a maximum entropy classifier. They utilized 203 abstracts from randomized trials for training and 124 abstracts for testing and achieved an F-score of $76 \%$.

Hara and Matsumoto [23] dealt with the problem of extracting "patient population" and "compared treatments" from medical abstracts. Given a sentence from the abstract, the authors first performed base noun-phrase chunking and then categorized the base noun-phrase into one of the five classes: "disease", "treatment", "patient", "study", and "others" using support vector machine and conditional random field models. After categorization, the authors used regular expression to extract the target words for patient population and comparison. The authors used 200 abstracts including terms such as "neoplasms" and "clinical trial, phase III" and obtained $91 \%$ accuracy for the task of noun phrase classification. For sentence classification, the authors obtained a precision of $80 \%$ for patient population and $82 \%$ for comparisons.

\section{Studies that identified only sentences but did not extract data elements from full-text reports}

Zhao et al. [24] used two classification tasks to extract study data including patient details, including one at the sentence level and another at the keyword level. The authors first used a five-class scheme including 1) patient, 2) result, 3) intervention, 4) study design, and 5) research goal and tried to classify sentences into one of these five classes. They further used six classes for keywords such as sex (e.g., male, female), age (e.g., 54-year-old), race (e.g., Chinese), condition (e.g., asthma), intervention, and study design (e.g., randomized trial). They utilized conditional random fields for the classification task. Using 19,893 medical abstracts and full-text articles from 17 journal websites, they achieved F-scores of $75 \%$ for identifying patients, $61 \%$ for intervention, $91 \%$ for results, $79 \%$ for study design, and $76 \%$ for research goal.

Hsu et al. [25] attempted to classify whether a sentence contains the "hypothesis", "statistical method", "outcomes", or "generalizability" of the study and then extracted the values. Using 42 full-text papers, the authors obtained F-scores of $86 \%$ for identifying hypothesis, $84 \%$ for statistical method, $90 \%$ for outcomes, and $59 \%$ for generalizability.

Song et al. [26] used machine learning-based classifiers such as maximum entropy classifier (MaxEnt), support vector machines (SVM), multi-layer perceptron (MLP), naive Bayes (NB), and radial basis function network (RBFN) to classify the sentences into categories such as analysis (statistical facts found by clinical experiment), general (generally accepted scientific facts, process, and methodology), recommendation (recommendations about interventions), and rule (guidelines). They utilized the principle of information gain (IG) as well as genetic algorithm (GA) for feature selection. They used 346 sentences from the clinical guideline document and obtained an Fscore of $98 \%$ for classifying sentences.

Marshall et al. [27] used soft-margin support vector machines in a joint model for risk of bias assessment along with supporting sentences for random sequence generation, allocation concealment, blinding of participants and personnel, and blinding of outcome assessment, among others. They utilized presence of unigrams in the supporting sentences as features in their model. Working with full text of 2200 clinical trials, the joint model achieved Fscores of $56,48,35$, and $38 \%$ for identifying sentences corresponding to random sequence generation, allocation concealment, blinding of participants and personnel, and blinding of outcome assessment, respectively.

\section{Studies that identified data elements only from abstracts but not from full texts}

Demner-Fushman and Lin [28] used a rule-based approach to identify sentences containing PICO. Using 275 manually annotated abstracts, the authors achieved an accuracy of $80 \%$ for population extraction and $86 \%$ for problem extraction. They also utilized a supervised classifier for outcome extraction and achieved accuracy from 64 to $95 \%$ across various experiments.

Kelly and Yang [29] used regular expressions and gazetteer to extract the number of participants, participant age, gender, ethnicity, and study characteristics. The authors utilized 386 abstracts from PubMed obtained with the query "soy and cancer" and achieved F-scores of $96 \%$ for identifying the number of participants, $100 \%$ for age of participants, $100 \%$ for gender of participants, $95 \%$ for ethnicity of participants, $91 \%$ for duration of study, and $87 \%$ for health status of participants. 
Hansen et al. [30] used support vector machines [31] to extract number of trial participants from abstracts of the randomized control trials. The authors utilized features such as part-of-speech tag of the previous and next words and whether the sentence is grammatically complete (contained a verb). Using 233 abstracts from PubMed, they achieved an F-score of $86 \%$ for identifying participants.

$\mathrm{Xu}$ et al. [32] utilized text classifications augmented with hidden Markov models [33] to identify sentences about subject demographics. These sentences were then parsed to extract information regarding participant descriptors (e.g., men, healthy, elderly), number of trial participants, disease/symptom name, and disease/symptom descriptors. After testing over 250 RCT abstracts, the authors obtained an accuracy of $83 \%$ for participant descriptors: $83 \%, 93 \%$ for number of trial participants, $51 \%$ for diseases/symptoms, and $92 \%$ for descriptors of diseases/symptoms.

Summerscales et al. [34] used a conditional random field-based approach to identify various named entities such as treatments (drug names or complex phrases) and outcomes. The authors extracted 100 abstracts of randomized trials from the $B M J$ and achieved F-scores of $49 \%$ for identifying treatment, $82 \%$ for groups, and $54 \%$ for outcomes.

Summerscales et al. [35] also proposed a method for automatic summarization of results from the clinical trials. The authors first identified the sentences that contained at least one integer (group size, outcome numbers, etc.). They then used the conditional random field classifier to find the entity mentions corresponding to treatment groups or outcomes. The treatment groups, outcomes, etc. were then treated as various "events." To identify all the relevant information for these events, the authors utilized templates with slots. The slots were then filled using a maximum entropy classifier. They utilized 263 abstracts from the $B M J$ and achieved F-scores of $76 \%$ for identifying groups, $42 \%$ for outcomes, $80 \%$ for group sizes, and $71 \%$ for outcome numbers.

\section{Studies that identified data elements from full-text reports}

Kiritchenko et al. [36] developed ExaCT, a tool that assists users with locating and extracting key trial characteristics such as eligibility criteria, sample size, drug dosage, and primary outcomes from full-text journal articles. The authors utilized a text classifier in the first stage to recover the relevant sentences. In the next stage, they utilized extraction rules to find the correct solutions. The authors evaluated their system using 50 full-text articles describing randomized trials with 1050 test instances and achieved a P5 precision of $88 \%$ for identifying the classifier. Precision and recall of their extraction rules was found to be 93 and $91 \%$, respectively.

Restificar et al. [37] utilized latent Dirichlet allocation [38] to infer the latent topics in the sample documents and then used logistic regression to compute the probability that a given candidate criterion belongs to a particular topic. Using 44,203 full-text reports of randomized trials, the authors achieved accuracies of 75 and $70 \%$ for inclusion and exclusion criteria, respectively.

Lin et al. [39] used linear-chain conditional random field for extracting various metadata elements such as number of patients, age group of the patients, geographical area, intervention, and time duration of the study. Using 93 full-text articles, the authors achieved a threefold cross validation precision of $43 \%$ for identifying number of patients, $63 \%$ for age group, $44 \%$ for geographical area, $40 \%$ for intervention, and $83 \%$ for time period.

De Bruijn et al. [40] used support vector machine classifier to first identify sentences describing information elements such as eligibility criteria, sample size, etc. The authors then used manually crafted weak extraction rules to extract various information elements. Testing this twostage architecture on 88 randomized trial reports, they obtained a precision of $69 \%$ for identifying eligibility criteria, $62 \%$ for sample size, $94 \%$ for treatment duration, $67 \%$ for intervention, $100 \%$ for primary outcome estimates, and $67 \%$ for secondary outcomes.

Zhu et al. [41] also used manually crafted rules to extract various subject demographics such as disease, age, gender, and ethnicity. The authors tested their method on 50 articles and for disease extraction obtained an F-score of 64 and $85 \%$ for exactly matched and partially matched cases, respectively.

\section{Risk of bias across studies}

In general, many studies have a high risk of selection bias because the gold standards used in the respective studies were not randomly selected. The risk of performance bias is also likely to be high because the investigators were not blinded. For the systems that used rule-based approaches, it was unclear whether the gold standard was used to train the rules or if there were a separate training set. The risk of attrition bias is unclear based on the study design of these non-randomized studies evaluating the performance of NLP methods. Lastly, the risk of reporting bias is unclear because of the lack of protocols in the development, implementation, and evaluation of NLP methods.

\section{Discussion}

\section{Summary of evidence \\ Extracting the data elements}

a. Participants-Sixteen studies explored the extraction of the number of participants $[12,13,16-20,23,24$, 
28-30, 32, 39], their age [24, 29, 39, 41], sex [24, 39], ethnicity [41], country [24, 39], comorbidities [21], spectrum of presenting symptoms, current treatments, and recruiting centers [21, 24, 28, 29, 32, 41], and date of study [39]. Among them, only six studies [28-30, 32, 39, 41] extracted data elements as opposed to highlighting the sentence containing the data element. Unfortunately, each of these studies used a different corpus of reports, which makes direct comparisons impossible. For example, Kelly and Yang [29] achieved high F-scores of $100 \%$ for age of participants, $91 \%$ for duration of study, $95 \%$ for ethnicity of participants, $100 \%$ for gender of subjects, $87 \%$ for health status of participants, and $96 \%$ for number of participants on a dataset of 386 abstracts.

b. Intervention-Thirteen studies explored the extraction of interventions $[12,13,16-20,22,24,28$, $34,39,40]$, intervention groups [34, 35], and intervention details (for replication if feasible) [36]. Of these, only six studies [28, 34-36, 39, 40] extracted intervention elements. Unfortunately again, each of these studies used a different corpus. For example, Kiritchenko et al. [36] achieved an F-score of 75-86\% for intervention data elements on a dataset of 50 full-text journal articles.

c. Outcomes and comparisons-Fourteen studies also explored the extraction of outcomes and time points of collection and reporting [12, 13, 16-20, 24, 25, $28,34-36,40]$ and extraction of comparisons [12, $16,22,23]$. Of these, only six studies [28, 34-36, 40] extracted the actual data elements. For example, De Bruijn et al. [40] obtained an F-score of $100 \%$ for extracting primary outcome and $67 \%$ for secondary outcome from 88 full-text articles. Summerscales [35] utilized 263 abstracts from the $B M J$ and achieved an F-score of $42 \%$ for extracting outcomes.

d. Results-Two studies [36, 40] extracted sample size data element from full text on two different data sets. De Bruijn et al. [40] obtained an accuracy of $67 \%$, and Kiritchenko et al. [36] achieved an F-score of $88 \%$.

e. Interpretation-Three studies explored extraction of overall evidence $[26,42]$ and external validity of trial findings [25]. However, all these studies only highlighted sentences containing the data elements relevant to interpretation.

f. Objectives-Two studies [24, 25] explored the extraction of research questions and hypotheses. However, both these studies only highlighted sentences containing the data elements relevant to interpretation.

g. Methods-Twelve studies explored the extraction of the study design $[13,18,20,24]$, study duration
[12, 29, 40], randomization method [25], participant flow [36, 37, 40], and risk of bias assessment [27]. Of these, only four studies [29, 36, 37, 40] extracted the corresponding data elements from text using different sets of corpora. For example, Restificar et al. [37] utilized 44,203 full-text clinical trial articles and achieved accuracies of 75 and $70 \%$ for inclusion and exclusion criteria, respectively.

h. Miscellaneous-One study [26] explored extraction of key conclusion sentence and achieved a high F-score of $98 \%$.

\section{Related reviews and studies}

Previous reviews on the automation of systematic review processes describe technologies for automating the overall process or other steps. Tsafnat et al. [43] surveyed the informatics systems that automate some of the tasks of systematic review and report systems for each stage of systematic review. Here, we focus on data extraction. None of the existing reviews [43-47] focus on the data extraction step. For example, Tsafnat et al. [43] presented a review of techniques to automate various aspects of systematic reviews, and while data extraction has been described as a task in their review, they only highlighted three studies as an acknowledgement of the ongoing work. In comparison, we identified 26 studies and critically examined their contribution in relation to all the data elements that need to be extracted to fully support the data extraction step.

Thomas et al. [44] described the application of text mining technologies such as automatic term recognition, document clustering, classification, and summarization to support the identification of relevant studies in systematic reviews. The authors also pointed out the potential of these technologies to assist at various stages of the systematic review. Slaughter et al. [45] discussed necessary next steps towards developing "living systematic reviews" rather than a static publication, where the systematic reviews can be continuously updated with the latest knowledge available. The authors mentioned the need for development of new tools for reporting on and searching for structured data from clinical trials.

Tsafnat et al. [46] described four main tasks in systematic review: identifying the relevant studies, evaluating risk of bias in selected trials, synthesis of the evidence, and publishing the systematic reviews by generating human-readable text from trial reports. They mentioned text extraction algorithms for evaluating risk of bias and evidence synthesis but remain limited to one particular method for extraction of PICO elements.

Most natural language processing research has focused on reducing the workload for the screening step of systematic reviews (Step 3). Wallace et al. [48, 
49] and Miwa et al. [50] proposed an active learning framework to reduce the workload in citation screening for inclusion in the systematic reviews. Jonnalagadda et al. [51] designed a distributional semantics-based relevance feedback model to semi-automatically screen citations. Cohen et al. [52] proposed a module for grouping studies that are closely related and an automated system to rank publications according to the likelihood for meeting the inclusion criteria of a systematic review. Choong et al. [53] proposed an automated method for automatic citation snowballing to recursively pursue relevant literature for helping in evidence retrieval for systematic reviews. Cohen et al. [54] constructed a voting perceptronbased automated citation classification system to classify each article as to whether it contains high-quality, drugspecific evidence. Adeva et al. [55] also proposed a classification system for screening articles for systematic review. Shemilt et al. [56] also discussed the use of text mining to reduce screening workload in systematic reviews.

\section{Research implications}

No standard gold standards or dataset

Among the 26 studies included in this systematic review, only three of them use a common corpus, namely 1000 medical abstracts from the PIBOSO corpus. Unfortunately, even that corpus facilitates only classification of sentences into whether they contain one of the data elements corresponding to the PIBOSO categories. No two other studies shared the same gold standard or dataset for evaluation. This limitation made it impossible for us to compare and assess the relative significance of the reported accuracy measures.

\section{Separate systems for each data element}

Few data elements, which are also relatively straightforward to extract automatically, such as the total number of participants (14 overall and 5 for extracting the actual data elements), have a relatively higher number of studies aiming towards extracting the same data element. This is not the case with other data elements. There are 27 out of 52 potential data elements that have not been explored for automated extraction, even if for highlighting the sentences containing them; seven more data elements were explored just by one study. There are 38 out of 52 potential data elements $(>70 \%)$ that have not been explored for automated extraction of the actual data elements; three more data elements were explored just by one study. The highest number of data elements extracted by a single study is only seven (14\%). This finding means that not only are more studies needed to explore the remaining $70 \%$ data elements, but that there is an urgent need for a unified framework or system to extract all necessary data elements. The current state of informatics research for data extraction is exploratory, and multiple studies need to be conducted using the same gold standard and on the extraction of the same data elements for effective comparison.

\section{Limitations}

Our study has limitations. First, there is a possibility that data extraction algorithms were not published in journals or that our search might have missed them. We sought to minimize this limitation by searching in multiple bibliographic databases, including PubMed, IEEExplore, and ACM Digital Library. However, investigators may have also failed to publish algorithms that had lower F-scores than were previously reported, which we would not have captured. Second, we did not publish a protocol a priori, and our initial findings may have influenced our methods. However, we performed key steps, including screening, full-text review, and data extraction in duplicate to minimize potential bias in our systematic review.

\section{Future work}

"On demand" access to summarized evidence and best practices has been considered a sound strategy to satisfy clinicians' information needs and enhance decisionmaking [57-65]. A systematic review of 26 studies concluded that information-retrieval technology produces positive impact on physicians in terms of decision enhancement, learning, recall, reassurance, and confirmation [62]. Slaughter et al. [45] discussed necessary next steps towards developing "living systematic reviews" rather than a static publication, where the systematic reviews can be continuously updated with the latest knowledge available. The authors mention the need for development of new tools for reporting on and searching for structured data from published literature. Automated information extraction framework that extract data elements have the potential to assist the systematic reviewers and to eventually automate the screening and data extraction steps.

Medical science is currently witnessing a rapid pace at which medical knowledge is being created-75 clinical trials a day [66]. Evidence-based medicine [67] requires clinicians to keep up with published scientific studies and use them at the point of care. However, it has been shown that it is practically impossible to do that even within a narrow specialty [68]. A critical barrier is that finding relevant information, which may be located in several documents, takes an amount of time and cognitive effort that is incompatible with the busy clinical workflow $[69,70]$. Rapid systematic reviews using automation technologies will enable clinicians with up-todate and systematic summaries of the latest evidence.

\section{Conclusions}

Our systematic review describes previously reported methods to identify sentences containing some of the data 
elements for systematic reviews and only a few studies that have reported methods to extract these data elements. However, most of the data elements that would need to be considered for systematic reviews have been insufficiently explored to date, which identifies a major scope for future work. We hope that these automated extraction approaches might first act as checks for manual data extraction currently performed in duplicate; then serve to validate manual data extraction done by a single reviewer; then become the primary source for data element extraction that would be validated by a human; and eventually completely automate data extraction to enable living systematic reviews.

\section{Appendix 1}

\section{Search strategies}

Below, we provide the search strategies used in PubMed, ACM Digital Library, and IEEExplore. The search was conducted on January 6, 2015.

\section{PubMed}

("identification" [Title] OR "extraction" [Title] OR "extracting" [Title] OR "detection" [Title] OR "identifying" [Title] OR "summarization" [Title] OR "learning approach" [Title] OR "automatically" [Title] OR "summarization" [Title] OR "identify sections" [Title] OR "learning algorithms" [Title] OR "Interpreting" [Title] OR "Inferring" [Title] OR "Finding" [Title] OR "classification" [Title]) AND ("medical evidence"[Title] OR "PICO"[Title] OR "PECODR" [Title] OR "intervention arms" [Title] OR "experimental methods" [Title] OR "study design parameters" [Title] OR "Patient oriented Evidence" [Title] OR "eligibility criteria" [Title] OR "clinical trial characteristics" [Title] OR "evidence based medicine" [Title] OR "clinically important elements" [Title] OR "evidence based practice" [Title] "results from clinical trials" [Title] OR "statistical analyses" [Title] OR "research results" [Title] OR "clinical evidence" [Title] OR "Meta Analysis" [Title] OR "Clinical Research" [Title] OR "medical abstracts" [Title] OR "clinical trial literature" [Title] OR "clinical trial characteristics" [Title] OR "clinical trial protocols" [Title] OR "clinical practice guidelines" [Title]).

\section{IEEE}

We performed this search only in the metadata.

("identification" OR "extraction" OR "extracting" OR "detection" OR "Identifying" OR "summarization" OR "learning approach" OR "automatically" OR "summarization" OR "identify sections" OR "learning algorithms" OR "Interpreting" OR "Inferring" OR "Finding" OR "classification") AND ("medical evidence" OR "PICO" OR "intervention arms" OR "experimental methods" OR "eligibility criteria" OR "clinical trial characteristics" OR "evidence based medicine" OR "clinically important elements" OR "results from clinical trials" OR "statistical analyses" OR "clinical evidence"
OR "Meta Analysis" OR "clinical research" OR "medical abstracts" OR "clinical trial literature" OR "clinical trial protocols").

\section{ACM digital library}

((Title: "identification" or Title: "extraction" or Title: "extracting" or Title: "detection" or Title: "Identifying" or Title: "summarization" or Title: "learning approach" or Title: "automatically" or Title: "summarization "or Title: "identify sections" or Title: "learning algorithms" or Title: "scientific artefacts" or Title: "Interpreting" or Title: "Inferring" or Title: "Finding" or Title: "classification" or "statistical techniques") and (Title: "medical evidence" or Abstract: "medical evidence" or Title: "PICO" or Abstract: "PICO" or Title: "intervention arms" or Title: "experimental methods" or Title: "study design parameters" or Title: "Patient oriented Evidence" or Abstract: "Patient oriented Evidence" or Title: "eligibility criteria" or Abstract: "eligibility criteria" or Title: "clinical trial characteristics" or Abstract: "clinical trial characteristics" or Title: "evidence based medicine" or Abstract: "evidence based medicine" or Title: "clinically important elements" or Title: "evidence based practice" or Title: "treatments" or Title: "groups" or Title: "outcomes" or Title: "results from clinical trials" or Title: "statistical analyses" or Abstract: "statistical analyses" or Title: "research results" or Title: "clinical evidence" or Abstract: "clinical evidence" or Title: "Meta Analysis" or Abstract:"Meta Analysis" or Title:"Clinical Research" or Title: "medical abstracts" or Title: "clinical trial literature" or Title: "Clinical Practice" or Title: "clinical trial protocols" or Abstract: "clinical trial protocols" or Title: "clinical questions" or Title: "clinical trial design")).

\section{Abbreviations}

NLP: natural language processing; ONSORT: CONsolidated Standards Of Reporting Trials; STARD: Standards for Reporting of Diagnostic Accuracy; PICO: Population, Intervention, Comparison, Outcomes; PECODR: PatientPopulation-Problem, Exposure-Intervention, Comparison, Outcome, Duration and Results; PIBOSO: Population, Intervention, Background, Outcome, Study Design, Other; CRF: conditional random fields; NB: naive Bayes;

RCT: randomized control trial; BMJ: British Medical Journal.

\section{Competing interests}

The authors declare that they have no competing interests.

\section{Authors' contributions}

SRJ and PG had full access to all the data in the study and take responsibility for the integrity of the data and the accuracy of the data analysis. Study concept and design were done by SRJ. SRJ, PG, and MDH did the acquisition, analysis, or interpretation of data. SRJ and PG drafted the manuscript. SRJ, PG, and MDH did the critical revision of the manuscript for important intellectual content. SRJ obtained funding. PG and SRJ provided administrative, technical, or material support. SRJ did the study supervision. All authors read and approved the final manuscript.

\section{Funding/Support}

This project was partly supported by the National Library of Medicine (grant 5ROOLM011389). The Cochrane Heart Group US Satellite at Northwestern University is supported by an intramural grant from the Northwestern University Feinberg School of Medicine. 


\section{Role of the sponsors}

The funding source had no role in the design and conduct of the study; collection, management, analysis, or interpretation of the data; preparation, review, or approval of the manuscript; and decision to submit the manuscript for publication.

\section{Disclaimer}

The content is solely the responsibility of the authors and does not necessarily represent the official views of the National Library of Medicine.

\section{Additional contributions}

Mark Berendsen (Research Librarian, Galter Health Sciences Library, Northwestern University Feinberg School of Medicine) provided insights on the design of this study, including the search strategies, and Dr. Kalpana Raja (Division of Health and Biomedical Informatics, Department of Preventive Medicine, Northwestern University Feinberg School of Medicine) reviewed the manuscript. None of them received compensation for their contributions.

\section{Author details}

'Division of Health and Biomedical Informatics, Department of Preventive Medicine, Northwestern University Feinberg School of Medicine, 750 North Lake Shore Drive, 11th Floor, Chicago, IL 60611, USA. ${ }^{2}$ Department of Computer Science and Engineering, Indian Institute of Technology, Kharagpur 721302 West Bengal, India. ${ }^{3}$ Department of Preventive Medicine, Northwestern University Feinberg School of Medicine, Chicago, USA.

\section{Received: 20 March 2015 Accepted: 21 May 2015}

\section{Published online: 15 June 2015}

\section{References}

1. Higgins J, Green S. Cochrane handbook for systematic reviews of interventions version 5.1. 0 [updated March 2011]. The Cochrane Collaboration. 2011. Available at [http://community.cochrane.org/handbook]

2. Khan KS, Ter Riet G, Glanville J, Sowden AJ, Kleijnen J. Undertaking systematic reviews of research on effectiveness: CRD's guidance for carrying out or commissioning reviews, NHS Centre for Reviews and Dissemination. 2001.

3. Woolf SH. Manual for conducting systematic reviews, Agency for Health Care Policy and Research. 1996

4. Field MJ, Lohr KN. Clinical practice guidelines: directions for a new program, Clinical Practice Guidelines. 1990.

5. Elliott J, Turner T, Clavisi O, Thomas J, Higgins J, Mavergames C, et al. Living systematic reviews: an emerging opportunity to narrow the evidencepractice gap. PLoS Med. 2014;11:e1001603.

6. Shojania KG, Sampson M, Ansari MT, Ji J, Doucette S, Moher D. How quickly do systematic reviews go out of date? A survival analysis. Ann Intern Med. 2007;147(4):224-33.

7. Hearst MA. Untangling text data mining. Proceedings of the 37 th annual meeting of the Association for Computational Linguistics. College Park, Maryland: Association for Computational Linguistics; 1999. p. 3-10.

8. Morton S, Levit L, Berg A, Eden J. Finding what works in health care: standards for systematic reviews. Washington D.C.: National Academies Press; 2011. Available at [http://www.nap.edu/catalog/13059/finding-whatworks-in-health-care-standards-for-systematic-reviews]

9. Begg C, Cho M, Eastwood S, Horton R, Moher D, Olkin I, et al. Improving the quality of reporting of randomized controlled trials: the CONSORT statement. JAMA. 1996;276(8):637-9.

10. Bossuyt PM, Reitsma JB, Bruns DE, Gatsonis CA, Glasziou PP, Irwig LM, et al. Towards complete and accurate reporting of studies of diagnostic accuracy: the STARD initiative. Clin Chem Lab Med. 2003;41(1):68-73. doi:10.1515/CCLM.2003.012.

11. Richardson WS, Wilson MC, Nishikawa J, Hayward RS. The well-built clinical question: a key to evidence-based decisions. ACP J Club. 1995;123(3):A12-3.

12. Dawes M, Pluye P, Shea L, Grad R, Greenberg A, Nie J-Y. The identification of clinically important elements within medical journal abstracts: PatientPopulation-Problem, Exposure-Intervention, Comparison, Outcome, Duration and Results (PECODR). Inform Prim Care. 2007;15(1):9-16.

13. Kim S, Martinez D, Cavedon L, Yencken L. Automatic classification of sentences to support evidence based medicine. BMC Bioinform. 2011;12 Suppl 2:S5.

14. Whiting P, Rutjes AWS, Reitsma JB, Bossuyt PMM, Kleijnen J. The development of QUADAS: a tool for the quality assessment of studies of diagnostic accuracy included in systematic reviews. BMC Med Res Methodol. 2003;3(1):25.

15. Lafferty J, McCallum A, Pereira F. Conditional random fields: probabilistic models for segmenting and labeling sequence data, Proceedings of the Eighteenth International Conference on Machine Learning. 2001. p. 282-9. \%L 3140.

16. Boudin F, Nie JY, Bartlett JC, Grad R, Pluye P, Dawes M. Combining classifiers for robust PICO element detection. BMC Med Inform Decis Mak. 2010;10:29. doi:10.1186/1472-6947-10-29.

17. Huang K-C, Liu C-H, Yang S-S, Liao C-C, Xiao F, Wong J-M, et al, editors. Classification of PICO elements by text features systematically extracted from PubMed abstracts. Granular Computing (GrC), 2011 IEEE International Conference on; 2011: IEEE.

18. Verbeke M, Van Asch V, Morante R, Frasconi P, Daelemans W, De Raedt L, editors. A statistical relational learning approach to identifying evidence based medicine categories. Proceedings of the 2012 Joint Conference on Empirical Methods in Natural Language Processing and Computational Natural Language Learning; 2012: Association for Computational Linguistics.

19. Huang K-C, Chiang IJ, Xiao F, Liao C-C, Liu CC-H, Wong J-M. PICO element detection in medical text without metadata: are first sentences enough? J Biomed Inform. 2013;46(5):940-6.

20. Hassanzadeh H, Groza T, Hunter J. Identifying scientific artefacts in biomedical literature: the evidence based medicine use case. J Biomed Inform. 2014;49:159-70.

21. Robinson DA. Finding patient-oriented evidence in PubMed abstracts. Athens: University of Georgia; 2012.

22. Chung GY-C. Towards identifying intervention arms in randomized controlled trials: extracting coordinating constructions. J Biomed Inform. 2009;42(5):790-800.

23. Hara $K$, Matsumoto $Y$. Extracting clinical trial design information from MEDLINE abstracts. N Gener Comput. 2007;25(3):263-75.

24. Zhao J, Bysani P, Kan MY. Exploiting classification correlations for the extraction of evidence-based practice information. AMIA Annu Symp Proc. 2012;2012:1070-8.

25. Hsu W, Speier W, Taira R. Automated extraction of reported statistical analyses: towards a logical representation of clinical trial literature. AMIA Annu Symp Proc. 2012;2012:350-9.

26. Song $\mathrm{MH}$, Lee $\mathrm{YH}$, Kang UG. Comparison of machine learning algorithms for classification of the sentences in three clinical practice guidelines. Healthcare Informatics Res. 2013;19(1):16-24.

27. Marshall IJ, Kuiper J, Wallace BC, editors. Automating risk of bias assessment for clinical trials. Proceedings of the 5th ACM Conference on Bioinformatics, Computational Biology, and Health Informatics; 2014: ACM.

28. Demner-Fushman D, Lin J. Answering clinical questions with knowledgebased and statistical techniques. Comput Linguist. 2007;33(1):63-103.

29. Kelly $\mathrm{C}$, Yang $\mathrm{H}$. A system for extracting study design parameters from nutritional genomics abstracts. J Integr Bioinform. 2013;10(2):222. doi:10.2390/biecoll-jib-2013-222

30. Hansen MJ, Rasmussen NO, Chung G. A method of extracting the number of trial participants from abstracts describing randomized controlled trials. J Telemed Telecare. 2008;14(7):354-8. doi:10.1258/jtt.2008.007007.

31. Joachims T. Text categorization with support vector machines: learning with many relevant features, Machine Learning: ECML-98, Tenth European Conference on Machine Learning. 1998. p. 137-42.

32. Xu R, Garten Y, Supekar KS, Das AK, Altman RB, Garber AM. Extracting subject demographic information from abstracts of randomized clinical trial reports. 2007.

33. Eddy SR. Hidden Markov models. Curr Opin Struct Biol. 1996;6(3):361-5.

34. Summerscales RL, Argamon S, Hupert J, Schwartz A. Identifying treatments, groups, and outcomes in medical abstracts. The Sixth Midwest Computational Linguistics Colloquium (MCLC 2009). 2009

35. Summerscales R, Argamon S, Bai S, Huperff J, Schwartzff A. Automatic summarization of results from clinical trials, the 2011 IEEE International Conference on Bioinformatics and Biomedicine (BIBM). 2011. p. 372-7.

36. Kiritchenko S, de Bruijn B, Carini S, Martin J, Sim I. ExaCT: automatic extraction of clinical trial characteristics from journal publications. BMC Med Inform Decis Mak. 2010;10:56.

37. Restificar A, Ananiadou S. Inferring appropriate eligibility criteria in clinical trial protocols without labeled data, Proceedings of the ACM sixth international workshop on Data and text mining in biomedical informatics. 2012. ACM. 
38. Blei DM, Ng AY, Jordan MI. Latent Dirichlet allocation. J Mach Learn Res. 2003;3(4-5):993-1022.

39. Lin S, Ng J-P, Pradhan S, Shah J, Pietrobon R, Kan M-Y, editors. Extracting formulaic and free text clinical research articles metadata using conditional random fields. Proceedings of the NAACL HLT 2010 Second Louhi Workshop on Text and Data Mining of Health Documents; 2010: Association for Computational Linguistics.

40. De Bruijn B, Carini S, Kiritchenko S, Martin J, Sim I, editors. Automated information extraction of key trial design elements from clinical trial publications. AMIA Annual Symposium Proceedings; 2008: American Medical Informatics Association.

41. Zhu H, Ni Y, Cai P, Qiu Z, Cao F. Automatic extracting of patient-related attributes: disease, age, gender and race. Stud Health Technol Inform. 2011;180:589-93.

42. Davis-Desmond P, Mollá D, editors. Detection of evidence in clinical research papers. Proceedings of the Fifth Australasian Workshop on Health Informatics and Knowledge Management-Volume 129; 2012: Australian Computer Society, Inc.

43. Tsafnat G, Glasziou P, Choong M, Dunn A, Galgani F, Coiera E. Systematic review automation technologies. Syst Rev. 2014;3(1):74.

44. Thomas J, McNaught J, Ananiadou S. Applications of text mining within systematic reviews. Res Synthesis Methods. 2011;2(1):1-14.

45. Slaughter $L$, Berntsen CF, Brandt L, Mavergames C. Enabling living systematic reviews and clinical guidelines through semantic technologies. D-Lib Magazine. 2015;21(1/2). Available at [http://www.dlib.org/dlib/january15/ slaughter/01slaughter.html]

46. Tsafnat G, Dunn A, Glasziou P, Coiera E. The automation of systematic reviews. BMJ. 2013:346:f139.

47. O'Mara-Eves A, Thomas J, McNaught J, Miwa M, Ananiadou S. Using text mining for study identification in systematic reviews: a systematic review of current approaches. Syst Rev. 2015;4(1):5

48. Wallace BC, Trikalinos TA, Lau J, Brodley C, Schmid CH. Semi-automated screening of biomedical citations for systematic reviews. BMC Bioinformatics. 2010;11(1):55.

49. Wallace BC, Small K, Brodley CE, Trikalinos TA, editors. Active learning for biomedical citation screening. Proceedings of the 16th ACM SIGKDD international conference on Knowledge discovery and data mining; 2010: ACM.

50. Miwa M, Thomas J, O'Mara-Eves A, Ananiadou S. Reducing systematic review workload through certainty-based screening. J Biomed Inform. 2014;51:242-53.

51. Jonnalagadda S, Petitti D. A new iterative method to reduce workload in systematic review process. Int J Comput Biol Drug Des. 2013;6(1-2):5-17. doi:10.1504/JJCBDD.2013.052198.

52. Cohen A, Adams C, Davis J, Yu C, Yu P, Meng W, et al. Evidence-based medicine, the essential role of systematic reviews, and the need for automated text mining tools. Proceedings of the 1st ACM International Health Informatics Symposium. 2010:376-80.

53. Choong MK, Galgani F, Dunn AG, Tsafnat G. Automatic evidence retrieval for systematic reviews. J Med Inter Res. 2014;16(10):e223.

54. Cohen AM, Hersh WR, Peterson K, Yen P-Y. Reducing workload in systematic review preparation using automated citation classification. J Am Med Inform Assoc. 2006;13(2):206-19.

55. García Adeva JJ, Pikatza Atxa JM, Ubeda Carrillo M, Ansuategi ZE. Automatic text classification to support systematic reviews in medicine. Expert Syst Appl. 2014:41(4):1498-508.

56. Shemilt I, Simon A, Hollands GJ, Marteau TM, Ogilvie D, O'Mara-Eves A, et al. Pinpointing needles in giant haystacks: use of text mining to reduce impractical screening workload in extremely large scoping reviews. Res Synthesis Methods. 2014;5(1):31-49.

57. Cullen RJ. In search of evidence: family practitioners' use of the Internet for clinical information. J Med Libr Assoc. 2002;90(4):370-9.

58. Hersh WR, Hickam DH. How well do physicians use electronic information retrieval systems? A framework for investigation and systematic review. JAMA. 1998;280(15):1347-52.

59. Lucas BP, Evans AT, Reilly BM, Khodakov Y, Perumal K, Rohr LG, et al. The impact of evidence on physicians' inpatient treatment decisions. J Gen Intern Med. 2004;19(5 Pt 1):402-9. doi:10.1111/j.1525-1497.2004.30306.x.

60. Magrabi F, Coiera EW, Westbrook Jl, Gosling AS, Vickland V. General practitioners' use of online evidence during consultations. Int J Med Inform. 2005;74(1):1-12. doi:10.1016/j.jimedinf.2004.10.003.
61. McColl A, Smith H, White P, Field J. General practitioner's perceptions of the route to evidence based medicine: a questionnaire survey. BMJ. 1998;316(7128):361-5.

62. Pluye P, Grad RM, Dunikowski LG, Stephenson R. Impact of clinical information-retrieval technology on physicians: a literature review of quantitative, qualitative and mixed methods studies. Int J Med Inform. 2005;74(9):745-68. doi:10.1016/j.jijmedinf.2005.05.004.

63. Rothschild JM, Lee TH, Bae T, Bates DW. Clinician use of a palmtop drug reference guide. J Am Med Inform Assoc. 2002;9(3):223-9.

64. Rousseau N, McColl E, Newton J, Grimshaw J, Eccles M. Practice based, longitudinal, qualitative interview study of computerised evidence based guidelines in primary care. BMJ. 2003;326(7384):314.

65. Westbrook JI, Coiera EW, Gosling AS. Do online information retrieval systems help experienced clinicians answer clinical questions? J Am Med Inform Assoc. 2005;12(3):315-21. doi:10.1197/jamia.M1717.

66. Bastian H, Glasziou P, Chalmers I. Seventy-five trials and eleven systematic reviews a day: how will we ever keep up? PLoS Med. 2010;7(9):e1000326. doi:10.1371/journal.pmed.1000326.

67. Lau J. Evidence-based medicine and meta-analysis: getting more out of the literature. In: Greenes RA, editor. Clinical decision support: the road ahead. 2007. p. 249

68. Fraser AG, Dunstan FD. On the impossibility of being expert. BMJ (Clinical Res). 2010;341:c6815

69. Ely JW, Osheroff JA, Chambliss ML, Ebell MH, Rosenbaum ME. Answering physicians' clinical questions: obstacles and potential solutions. J Am Med Inform Assoc. 2005:12(2):217-24. doi:10.1197/jamia.M1608.

70. Ely JW, Osheroff JA, Maviglia SM, Rosenbaum ME. Patient-care questions that physicians are unable to answer. J Am Med Inform Assoc. 2007;14(4):407-14. doi:10.1197/jamia.M2398.

\section{Submit your next manuscript to BioMed Central and take full advantage of:}

- Convenient online submission

- Thorough peer review

- No space constraints or color figure charges

- Immediate publication on acceptance

- Inclusion in PubMed, CAS, Scopus and Google Scholar

- Research which is freely available for redistribution 